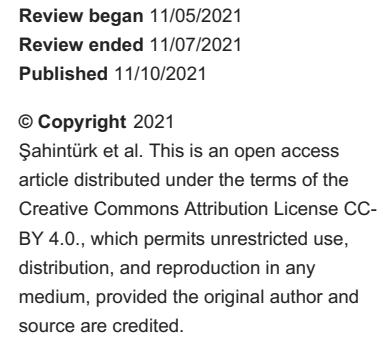

\section{Neurologic Complications in Heart Transplant Recipients Readmitted to the Intensive Care Unit}

\author{
Helin Şahintürk ${ }^{1}$, Beyza Meltem Yurtsever ${ }^{1}$, Özgür Ersoy ${ }^{2}$, Seda Kibaroğlu ${ }^{3}$, Pınar Zeyneloğlu ${ }^{1}$ \\ 1. Anesthesiology and Critical Care, Başkent University Faculty of Medicine, Ankara, TUR 2. Cardiovascular Surgery, \\ Dışkapı Yıldırım Beyazıd Eğitim ve Araştırma Hastanesi, Ankara, TUR 3. Neurology, Başkent University Faculty of \\ Medicine, Ankara, TUR
}

Corresponding author: Helin Şahintürk, helinsahinturk@yahoo.com

\section{Abstract}

\section{Introduction}

Neurologic complications after transplantation surgery are major causes of morbidity, and the incidence of neurologic complications among heart transplant recipients varies from $7 \%$ to $81 \%$.

In our study, we aimed to determine the incidence, etiologies, and risk factors of neurologic complications among patients readmitted to the intensive care unit (ICU) after heart transplantation.

\section{Method}

In this retrospective cohort study, the medical records of all patients who underwent cardiac transplantation from February 2003 to July 2019 were reviewed, and those admitted to the ICU due to neurologic complications during the early and late postoperative period were evaluated. The patients were divided into two groups based on the development of neurologic complications to compare demographic and other characteristics.

\section{Results}

A total of 130 heart transplant recipients were analyzed. We excluded 33 patients from the study because they either had neurologic complications or died postoperatively without discharge from the intensive care unit. The mean age of the cohort was $35.4 \pm 18.5$ years, and 74 (76.3\%) were male. Out of those 97 heart transplant recipients, 22 (22.7\%) developed neurologic complications. Five patients $(22.7 \%)$ were admitted to the ICU in the first month, six patients (27.3\%) were admitted to the ICU between one and six months, and 11 patients (50\%) were admitted to the ICU six months after transplantation due to neurologic complications. The most common diagnosis was posterior reversible encephalopathy syndrome (PRES) $(n=$ $6,27.3 \%)$. The other diagnoses were calcineurin inhibitor toxicity $(n=5,22.7 \%)$, intracranial hemorrhage ( $n$ $=3,13.6 \%)$, seizures $(n=2,9.2 \%)$, stroke $(n=2,9.2 \%)$, femoral neuropathy $(n=1,4.5 \%)$, myopathy $(n=1$, $4.5 \%)$, phrenic nerve damage $(n=1,4.5 \%)$, and cerebral abscess $(n=1,4.5 \%)$. The rate of neurologic complications was higher in males when compared with females $(\mathrm{p}=0.03)$. Both groups were similar in terms of the etiologies of cardiac failure, coexisting disease, and anticoagulant and immunosuppressive usage. The requirement for mechanical ventilation, renal replacement therapy, and the incidence of acute kidney injury were similar in both groups $(p>0.05)$. The incidence of sepsis was significantly higher in patients with neurologic complications $(n=8,36.4 \%$, versus $n=5,6.7 \%$; $<0.001$ ). The mean length of hospital stay was significantly higher in patients with neurologic complications (21.4 \pm 15.8 versus $11.1 \pm 13.3$ days, $\mathrm{p}=0.01$ ).

The risk of developing neurologic complications is 3.036 times higher in males, and this is statistically significant (odds ratio (OR), 3.036; 95\% confidence interval (CI), 1.078-8.444; $\mathrm{p}=0.036$ ).

\section{Conclusion}

Our results suggest that neurologic complications develop in $22.7 \%$ of heart transplant recipients admitted to the ICU, and half of them are seen after six months postoperatively. PRES was the most frequent (27.3\%) neurologic complication. The risk of neurologic complications is three times higher for males. The mean length of hospital stay and incidence of sepsis were significantly higher in heart transplant recipients who developed neurologic complications.

Categories: Anesthesiology, Neurology, Transplantation

Keywords: transplantation, icu, intensive care unit, heart transplantation, neurologic complications

\section{Introduction}

Heart failure, which affects millions of people worldwide, should be considered a global health priority $[1,2]$. 
Heart transplantation is the main treatment method in patients with end-stage heart failure in whom all treatment modalities are insufficient [3]. The incidence of neurologic complications after heart transplantation varies between $7 \%$ and $81 \%$ [4-6]. Cerebrovascular complications such as ischemic stroke or transient ischemic attack are usually observed. There are reports that the most common neurologic complication after cardiac transplantation is posterior reversible encephalopathy syndrome (PRES) and develops secondary to immunosuppressive therapy [6].

Heart transplantation has been performed in our clinic since 2003. Recently, the rate of heart transplantation has increased in our country and in the world. Our clinical observation is that patients have a high incidence of neurologic complications after heart transplantation.

Although there are publications about neurologic complications after heart transplantation, we aimed to determine the neurologic complications, incidence, and risk factors among patients readmitted to the intensive care unit (ICU) after heart transplantation.

\section{Materials And Methods}

This study was approved by Başkent University Institutional Review Board (KA 19/205) and supported by Başkent University Research Fund. In this retrospective cohort study, the medical records of all patients who underwent cardiac transplantation from February 2003 to July 2019 were reviewed. Among those, patients admitted to the ICU due to neurologic complications during the early and late postoperative period were evaluated. Patients who developed neurologic complications before discharge from the intensive care unit after surgery and who died in the early postoperative period without discharge from the intensive care unit were excluded from the study. The patients were divided into two groups based on the development of neurologic complications to compare demographic and other characteristics. The collected data included the demographic characteristics of patients (age, gender, body weight, and body height), comorbidities, drugs, perioperative laboratory values and hemodynamic parameters, intraoperative features, length of mechanical ventilation, lengths of ICU/hospital stay, and hospital mortality.

The same opioid-based anesthesia technique was used in all heart transplant recipients. Anesthesia was induced with midazolam 0.02-0.05 mg/kg intravenous (i.v.), fentanyl $500 \mu \mathrm{g}$ i.v., and rocuronium bromide 0.6-1 mg/kg i.v. Desflurane at a concentration of $4 \%-6 \%$ and fentanyl $5 \mu \mathrm{g} / \mathrm{kg} / \mathrm{h}$ were used for the maintenance of anesthesia. In all cases, our clinical protocols for standard cardiopulmonary bypass (CPB) surgery and standard perfusion techniques were used. Carbon dioxide insufflation within the surgical field was used to prevent microemboli. Following surgery, all patients were admitted to the intensive care unit intubated and mechanically ventilated. The same surgical, anesthesia, and intensivist teams were assigned during the perioperative period for all heart transplantation surgeries.

The patients who developed neurologic complications were divided into three groups according to the time of development: those who developed neurologic complications in the first month, between one and six months, and after six months. Neurologic complications were evaluated as early postoperative complications in the first month and late postoperative complications after six months.

Data were summarized as mean \pm standard deviation and median (range) for continuous variables and frequencies (percentiles) for categorical variables. Student's t-test or Mann-Whitney U test was used for independent group comparisons, depending on the distributional properties of the data. The Chi-square test was used for proportions, and its counterpart, Fisher's exact test, was used when the data were sparse. To define risk factors for the outcome variable (neurologic complications), multiple logistic regression analysis was used, and adjusted odds ratios (ORs) and their confidence intervals (CIs) were calculated. All analyses were performed using IBM SPSS Statistics for Windows, version 20.0. A p value $<0.05$ was considered statistically significant.

\section{Results}

A total of 130 heart transplant recipients were analyzed. We excluded 33 patients from the study because they either had neurologic complications postoperatively without discharge from the intensive care unit or they died postoperatively without discharge from the intensive care unit. The mean age of the cohort was $35.4 \pm 18.5$ years, and 74 (76.3\%) were male. The demographic characteristics and main diagnosis of the patients included in the study are shown in Table 1 . 


\section{Cureus}

\begin{tabular}{|l|l|}
\hline & $\mathbf{n = 9 7}(\%)$ \\
\hline Age (years) & $35.4 \pm 18.5$ \\
\hline Male & $74(76.3 \%)$ \\
\hline Diagnosis & $59(60.8 \%)$ \\
\hline Dilated cardiomyopathy & $12(12.4 \%)$ \\
Restrictive cardiomyopathy & $15(15.5 \%)$ \\
Ischemic cardiomyopathy & $3(3.1 \%)$ \\
Myocarditis & $7(7.2 \%)$ \\
Congenital heart disease & $1(1 \%)$ \\
Arrhythmogenic right ventricular cardiomyopathy & \\
\hline
\end{tabular}

TABLE 1: Demographic characteristics and main diagnosis of the study population [mean \pm SD or n (\%)]

Out of those 97 heart transplant recipients, 22 (23.7\%) developed neurologic complications. Five patients (22.7\% ) were admitted to the ICU in the first month, six patients $(27.3 \%)$ were admitted to the ICU between one and six months, and 11 patients (50\%) were admitted to the ICU six months after transplantation due to neurologic complications (Table 2).

\begin{tabular}{|l|l|l|}
\hline Postoperative & $\mathbf{n}(\mathbf{2 2})$ & \% (100\%) \\
\hline One month & 5 & 22.7 \\
\hline One to six months & 6 & 27.3 \\
\hline$>$ months & 11 & 50 \\
\hline
\end{tabular}

\section{TABLE 2: Timing of neurologic complications}

The most common diagnosis was PRES $(\mathrm{n}=6,27.3 \%)$. The other diagnoses were calcineurin inhibitor toxicity $(n=5,22.7 \%)$, intracranial hemorrhage $(n=3,13.6 \%)$, seizures $(n=2,9.2 \%)$, stroke $(n=2,9.2 \%)$, femoral neuropathy $(\mathrm{n}=1,4.5 \%)$, myopathy $(\mathrm{n}=1,4.5 \%)$, phrenic nerve damage $(\mathrm{n}=1,4.5 \%)$, and cerebral abscess $(\mathrm{n}=1,4.5 \%)$ (Table 3). 


\section{Cureus}

\begin{tabular}{|l|l|l|}
\hline & $\mathbf{n}(\mathbf{2 2})$ & \% (100\%) \\
\hline PRES & 6 & 27.3 \\
\hline Calcineurin inhibitor toxicity & 5 & 22.7 \\
\hline Hemorrhage & 3 & 13.6 \\
\hline Seizures & 2 & 9.2 \\
\hline Stroke & 2 & 9.2 \\
\hline Femoral neuropathy & 1 & 4.5 \\
\hline Phrenic nerve damage & 1 & 4.5 \\
\hline Myopathy & 1 & 4.5 \\
\hline Brain abscess & 1 & 4.5 \\
\hline
\end{tabular}

\section{TABLE 3: Neurologic complications}

PRES: posterior reversible encephalopathy syndrome

The rate of neurologic complications was higher in males than in females $(p=0.03)$. There was no difference in the frequency of neurologic complications between patients $\leqslant 18$ years and $>18$ years $(p=0.754)$.

Both groups were similar in terms of the etiologies of cardiac failure, coexisting disease, and anticoagulant and immunosuppressive usage (Table 4). 


\section{Cureus}

\begin{tabular}{|c|c|c|c|c|}
\hline & & NC (-) & NC (+) & $\mathbf{p}$ \\
\hline \multirow{2}{*}{ Age } & $\leq 18$ & $18(24)$ & $6(27.3)$ & \multirow{2}{*}{0.754} \\
\hline & $>18$ & $57(76)$ & 16 (72.7) & \\
\hline \multirow{2}{*}{ Gender } & Male & $61(81.3)$ & $13(59.1)$ & \multirow{2}{*}{$0.031^{* *}$} \\
\hline & Female & $14(18.7)$ & $9(40.9)$ & \\
\hline \multirow{6}{*}{ Etiologies } & ICMP & $14(18.7)$ & $1(4.5)$ & \multirow{6}{*}{$0.086^{*}$} \\
\hline & DCMP & $40(53.3)$ & $19(86.5)$ & \\
\hline & RCMP & $11(14.7)$ & $1(4.5)$ & \\
\hline & Myocarditis & $2(2.7)$ & $1(4.5)$ & \\
\hline & Congenital & $7(9.3)$ & $0(0)$ & \\
\hline & ARVC & $1(1.3)$ & $0(0)$ & \\
\hline \multirow{8}{*}{ Coexisting disease } & HTN & $4(5.3)$ & $2(9.1)$ & \multirow{8}{*}{$0.222^{*}$} \\
\hline & Pulmonary HTN & $5(6.7)$ & $1(4.5)$ & \\
\hline & DM & $1(1.3)$ & $1(4.5)$ & \\
\hline & Cardiac failure & $55(73.5)$ & $12(54.5)$ & \\
\hline & Chronic renal failure & $1(1.3)$ & $0(0)$ & \\
\hline & Malignancy & $1(1.3)$ & $1(4.5)$ & \\
\hline & Arrhythmia & $4(5.3)$ & $1(4.5)$ & \\
\hline & Others & $4(5.3)$ & $4(18.2)$ & \\
\hline \multirow{3}{*}{ Immunosuppressive agent } & Tacrolimus & $59(78.7)$ & $17(77.3)$ & \multirow{3}{*}{$0.788^{*}$} \\
\hline & Cyrolimus & $13(17.3)$ & $5(22.7)$ & \\
\hline & Cyclosporine & $3(4)$ & $0(0)$ & \\
\hline
\end{tabular}

\section{TABLE 4: Comparison of the two groups in terms of demographics, etiologies, coexisting}

disease, and immunosuppressive drugs [mean \pm SD or $n(\%)$ ]

*p value of Fisher's exact test

${ }^{* *} p$ value $<0.05$

NC: neurologic complications, ICMP: ischemic cardiomyopathy, DCMP: dilated cardiomyopathy, RCMP: restrictive cardiomyopathy, ARVC: arrhythmogenic right ventricular cardiomyopathy, HTN: hypertension, DM: diabetes mellitus

The requirement for mechanical ventilation, renal replacement therapy, and the incidence of acute kidney injury were similar in the two groups $(p>0.05$ ) (Table 5). The incidence of sepsis was significantly higher in patients with neurologic complications $(n=8,36.4 \%$, versus $n=5,6.7 \% ; p<0.001)$. The mean length of hospital stay was significantly higher in patients with neurologic complications $(21.4 \pm 15.8$ versus $11.1 \pm$ 13.3 days, $p=0.01$ ), but the mean length of ICU stay was similar in both groups $(8.8 \pm 8.7$ versus $9.1 \pm 12.3$ days, $\mathrm{p}=0.9)$. Hospital mortality $(50 \%$ versus $44 \%, \mathrm{p}=0.6)$ and 30 -day mortality $(27.7 \%$ versus $41.3 \%, \mathrm{p}=$ 0.1 ) were not different in the two groups (Table 5). 


\section{Cureus}

\begin{tabular}{|c|c|c|c|}
\hline & NC (-) & NC $(+)$ & $\mathbf{p}$ \\
\hline Sepsis & $5(6.7 \%)$ & $8(36.4 \%)$ & $<0.001^{* *}$ \\
\hline AKI & $19(25.3 \%)$ & $4(18.2 \%)$ & 0.488 \\
\hline RRT requirement & $17(22.7 \%)$ & $3(13.6 \%)$ & 0.357 \\
\hline Need for intubation & $33(44 \%)$ & $10(45.5 \%)$ & 0.904 \\
\hline Need for MV & $34(45.3 \%)$ & $11(50 \%)$ & 0.700 \\
\hline Duration of MV (hours) & $r \pm 10.24$ & $4.90 \pm 5.26$ & 0.714 \\
\hline Tracheostomy & $7(9.3 \%)$ & $1(4.5 \%)$ & 0.473 \\
\hline Organ deficiency & $20(27 \%)$ & $7(31.8 \%)$ & 0.661 \\
\hline Use of vasopressors & $30(40 \%)$ & $8(36.4 \%)$ & 0.759 \\
\hline Neurologic deficit & $0(0 \%)$ & $1(4.5 \%)$ & $0.227^{*}$ \\
\hline Length of ICU stay (days) & $9.08 \pm 12.28$ & $8.76 \pm 8.72$ & 0.970 \\
\hline Length of hospital stay (days) & $11.08 \pm 13.25$ & $21.40 \pm 15.77$ & $0.015^{\star \star}$ \\
\hline Mortality (30 days) & $31(41.3 \%)$ & $5(27.1 \%)$ & 0.112 \\
\hline ICU mortality & $33(44 \%)$ & $7(31.8 \%)$ & 0.307 \\
\hline Hospital mortall & & & \\
\hline
\end{tabular}

\section{TABLE 5: Comparison between the two groups in terms of outcomes [mean \pm SD or $\mathbf{n}(\%)$ ]}

* $p$ value of Fisher's exact test

${ }^{* *} \mathrm{p}$ value $<0.05$

NC: neurologic complications, AKI: acute kidney injury, RRT: renal replacement therapy, MV: mechanical ventilation, ICU: intensive care unit

We argue that using a univariate logistic regression model, gender-differentiated sample groups show statistically significant differences in the development of neurologic complications. We found that the risk of developing neurologic complications is 3.036 times higher in males, and this is statistically significant (odds ratio (OR), 3.036; 95\% confidence interval $(\mathrm{CI}), 1.078-8.444 ; \mathrm{p}=0.036$ ) (Table 6 ).

\begin{tabular}{|l|c|c|c|c|c|}
\hline Variables & B & S. error & Exp (B) & Min $\mathbf{C l}$ & Max \\
\hline Gender (male) & 1.104 & 0.525 & 3.036 & 1.078 & 8.444 \\
\hline
\end{tabular}

\section{TABLE 6: Univariate logistic regression results}

${ }^{* *}$ p value $<0.05$

B: regression coefficient, Exp (B): odds ratio, S. error: standard error of regression coefficient (B), Min: minimum, Max: maximum, Cl: confidence interval

\section{Discussion}

In this retrospective review of 97 heart transplant recipients, the incidence of neurologic complications was estimated to be $23.7 \%$, and $50 \%$ of them developed after six months after transplantation. The most common diagnosis was PRES. The incidence of sepsis was significantly higher in patients with neurologic complications. Being male increased the risk of neurologic complications three times. It was also established that the mean length of hospital stay was significantly higher in patients with neurologic complications. 
In our study, the incidence of neurologic complications after heart transplantation was found to be $23.7 \%$. In the literature, neurologic deficit incidence after heart transplantation varies from $7 \%$ to $81 \%$ [7-9]. We believe that the reason for this is the difference in the duration of the studies. van de Beek et al. showed that the risk of neurologic complications increased up to $81 \%$ in 15 years following heart transplantation [9]. In our study, it was found that half of the emergent neurologic complications developed after six months. In line with the findings of van de Beek et al., we think that the risk of complication development increases with time. In the literature, complications such as ischemic stroke, hemorrhagic stroke, and transient ischemic attack were mostly reviewed. Therefore, we also analyzed the incidences of seizure, calcineurin toxicity, encephalopathy, neuropathy, myopathy, and phrenic nerve damage. Thus, the reason for a higher incidence of neurologic complications in our cohort compared with other studies might be this approach.

There are publications reporting that the most frequent neurologic complication after cardiac transplantation is ischemic stroke, as well as publications reporting that the most common complication is encephalopathy $[6,7,10]$. The most common cause of encephalopathy has been reported as PRES $[6,10]$. In our study, the most common neurologic complication after heart transplantation was found to be PRES. PRES is a clinicoradiological syndrome that includes symptoms such as headache, seizure, changes in consciousness, and visual impairment [11]. Calcineurin inhibitors can have neurologic side effects even at normal serum levels without toxicity, and PRES is one of these neurologic side effects [12]. In addition to immunosuppressive therapy, renal failure and hypertension can lead to PRES development.

In our study, it has been shown that the frequency of neurologic complications is three times higher in male patients. Publications reveal that cardiac failure and morbidity after cardiac surgery is more frequent among women $[2,13,14]$. However, some publications advocate that there is no gender difference in the development of complications after cardiac surgery, and there are also publications reporting that neurologic complications are more frequent in male patients, similar to our study [15-18]. In their studies, Hogue et al. reported that neurologic complications were more common in women than in men, in which they investigated the effects of gender differences in neurologic outcomes and mortality after cardiac surgery, and that this was because female patients were older than male patients and had a higher rate of underlying diseases [19]. Woods et al. investigated the effect of gender on patients' outcomes after coronary artery bypass grafting and reported that the mortality and morbidity rates in women were higher than in men. They reported that the reason for this was that women had more comorbidities than men; however, they found that only neurologic complications were more common in male patients [17]. In our study, unlike Hogue et al., we found that male patients developed more neurologic complications. We attribute this to the fact that in our study population, there was no difference in men and women in terms of age and concomitant diseases.

Neurologic complications developing after heart transplantation have effects on morbidity and mortality [10]. In our study, the fact that the hospitalization duration of cardiac transplant recipients who developed neurologic complications was statistically significantly longer than that of the group without neurologic complications also coincides with this information. Additionally, the frequency of sepsis was found to be higher in the patient group with neurologic complications compared with the group without complications. We think that the reason for this is related to prolonged hospitalization. Prolonged hospitalization increases the incidence of sepsis, and sepsis increases the duration of hospitalization as well [20,21].

Limitations of this study include its retrospective, single-center nature and limited size. Future prospective studies should include larger patient groups.

\section{Conclusions}

Our results suggest that neurologic complications develop in $22.7 \%$ of heart transplant recipients admitted to the ICU and that half of them are seen after six month postoperatively. PRES was the most frequent (27.3\%) neurologic complication. The risk of neurologic complications is three times higher in the male population. The mean length of hospital stay and incidence of sepsis were significantly higher in heart transplant recipients who developed neurologic complications.

\section{Additional Information \\ Disclosures}

Human subjects: Consent was obtained or waived by all participants in this study. Başkent University Faculty of Medicine Ethics Committee issued approval KA 19/205. Animal subjects: All authors have confirmed that this study did not involve animal subjects or tissue. Conflicts of interest: In compliance with the ICMJE uniform disclosure form, all authors declare the following: Payment/services info: All authors have declared that no financial support was received from any organization for the submitted work. Financial relationships: All authors have declared that they have no financial relationships at present or within the previous three years with any organizations that might have an interest in the submitted work. Other relationships: All authors have declared that there are no other relationships or activities that could appear to have influenced the submitted work. 


\section{References}

1. Ponikowski P, Anker SD, AlHabib KF, et al.: Heart failure: preventing disease and death worldwide . ESC Heart Fail. 2014, 1:4-25. 10.1002/ehf2.12005

2. Savarese G, Lund LH: Global public health burden of heart failure . Card Fail Rev. 2017, 3:7-11. 10.15420/cfr.2016:25:2

3. Deng MC: Cardiac transplantation. Heart. 2002, 87:177-84. 10.1136/heart.87.2.177

4. Zivković SA, Abdel-Hamid H: Neurologic manifestations of transplant complications . Neurol Clin. 2010, 28:235-51. 10.1016/j.ncl.2009.09.011

5. Malheiros SM, Almeida DR, Massaro AR, et al.: Neurologic complications after heart transplantation. Arq Neuropsiquiatr. 2002, 60:192-7. 10.1590/s0004-282x2002000200002

6. Öcal R, Kibaroğlu S, Derle E, et al.: Neurologic complications after cardiac transplant. Exp Clin Transplant. 2016, 10.6002/ect.2016.0127

7. Belvís R, Martí-Fàbregas J, Cocho D, et al.: Cerebrovascular disease as a complication of cardiac transplantation. Cerebrovasc Dis. 2005, 19:267-71. 10.1159/000084091

8. Pérez-Miralles F, Sánchez-Manso JC, Almenar-Bonet L, Sevilla-Mantecón T, Martínez-Dolz L, VílchezPadilla JJ: Incidence of and risk factors for neurologic complications after heart transplantation . Transplant Proc. 2005, 37:4067-70. 10.1016/j.transproceed.2005.09.162

9. van de Beek D, Kremers W, Daly RC, Edwards BS, Clavell AL, McGregor CG, Wijdicks EF: Effect of neurologic complications on outcome after heart transplant. Arch Neurol. 2008, 65:226-31. 10.1001/archneurol.2007.52

10. Alejaldre A, Delgado-Mederos R, Santos MÁ, Martí-Fàbregas J: Cerebrovascular complications after heart transplantation. Curr Cardiol Rev. 2010, 6:214-7. 10.2174/157340310791658811

11. Sudulagunta SR, Sodalagunta MB, Kumbhat M, Settikere Nataraju A: Posterior reversible encephalopathy syndrome(PRES). Oxf Med Case Reports. 2017, 2017:omx011. 10.1093/omcr/omx011

12. Sonneville R, Mariotte E, Brouwer MC: Cerebral complications of solid organ transplantation. Intensive Care Med. 2019, 45:394-7. 10.1007/s00134-019-05540-1

13. Borlaug BA, Redfield MM: Diastolic and systolic heart failure are distinct phenotypes within the heart failure spectrum. Circulation. 2011, 123:2006-13; discussion 2014. 10.1161/CIRCULATIONAHA.110.954388

14. Scantlebury DC, Borlaug BA: Why are women more likely than men to develop heart failure with preserved ejection fraction?. Curr Opin Cardiol. 2011, 26:562-8. 10.1097/HCO.0b013e32834b7faf

15. Aldea GS, Gaudiani JM, Shapira OM, et al.: Effect of gender on postoperative outcomes and hospital stays after coro- nary artery bypass grafting. Ann Thorac Surg. 1999, 67:1097- 103. 10.1016/s0003-4975(99)000557

16. Fox AA, Nussmeier NA: Does gender influence the likelihood or types of complications following cardiac surgery?. Semin Cardiothorac Vasc Anesth. 2004, 8:283-95. 10.1177/108925320400800403

17. Woods SE, Noble G, Smith JM, Hasselfeld K: The influence of gender in patients undergoing coronary artery bypass graft surgery: an eight-year prospective hospitalized cohort study. J Am Coll Surg. 2003, 196:428-34. 10.1016/S1072-7515(02)01756-8

18. Raffa GM, Agnello F, Occhipinti G, et al.: Neurological complications after cardiac surgery: a retrospective case-control study of risk factors and outcome. J Cardiothorac Surg. 2019, 14:23. 10.1186/s13019-019-08448

19. Hogue CW Jr, Barzilai B, Pieper KS, Coombs LP, DeLong ER, Kouchoukos NT, Dávila-Román VG: Sex differences in neurological outcomes and mortality after cardiac surgery: a society of thoracic surgery national database report. Circulation. 2001, 103:2133-7. 10.1161/01.cir.103.17.2133

20. Esteban A, Frutos-Vivar F, Ferguson ND, et al.: Sepsis incidence and outcome: contrasting the intensive care unit with the hospital ward. Crit Care Med. 2007, 35:1284-9. 10.1097/01.CCM.0000260960.94300.DE

21. Vincent JL, Rello J, Marshall J, et al.: International study of the prevalence and outcomes of infection in intensive care units. JAMA. 2009, 302:2323-9. 10.1001/jama.2009.1754 